\title{
Composition of Secondary Metabolites in Various Parts of 'Seolhyang' Strawberry Plants
}

\author{
Dong Sub Kim ${ }^{1 \dagger}$, Haeyoung $\mathrm{Na}^{2 \dagger}$, Yurina Kwack ${ }^{3}$, Sung Kyeom Kim ${ }^{3}$, \\ Jeong Wook Heo ${ }^{4}$, and Changhoo Chun ${ }^{1,3 *}$ \\ ${ }^{1}$ Department of Plant Science, Seoul National University, Seoul 151-921, Korea \\ ${ }^{2}$ Department of Horticultural Science, Mokpo National University, Muan 534-729, Korea \\ ${ }^{3}$ Research Institute for Agriculture and Life Sciences, Seoul National University, Seoul 151-921, Korea \\ ${ }^{4}$ Farming Automation Division, Department of Agricultural Engineering, National Academy of Agricultural Science, \\ Rural Development Administration, Suwon 441-707, Korea
}

\begin{abstract}
The objective of this study was to identify the content of phenolic and volatile organic compounds in edible and non-edible parts of 'Seolhyang' strawberry plants. We performed a comparative chemical analysis of the compounds found in roots, leaves, petioles, runners, and unripe and ripe fruits during vegetative propagation and reproductive growth. The contents of ellagic and gallic acids in the leaves of runner plants during vegetative propagation were $7.36 \pm 1.10$ and $5.07 \pm 3.66 \mathrm{mg} \cdot \mathrm{g}^{-1} \mathrm{FW}$, respectively, and were higher than those in the other parts. The main volatile organic compound was identified as 3-hexen-1-ol, and it was mostly detected in leaves. The content of ellagic acid in leaves during reproductive growth was $12.96 \pm 2.30 \mathrm{mg} \cdot \mathrm{g}^{-1} \mathrm{FW}$, while that in the other parts was below $6.00 \mathrm{mg} \cdot \mathrm{g}^{-1} \mathrm{FW}$. The content of gallic acid in unripe fruits was $2.75 \pm 0.48 \mathrm{mg} \cdot \mathrm{g}^{-1} \mathrm{FW}$ and was higher than that in the other parts. Ripe fruits contained the lowest contents of ellagic and gallic acids but contained the most diverse volatile organic compounds, including sesquiterpenes, among the tested plant parts. The results indicate that non-edible parts (e.g., leaves and unripe fruits) of strawberry plants can be used as a raw material for antioxidant and anti-inflammatory agents, and edible parts (i.e., ripe fruits) can be available for making an essential oil.
\end{abstract}

Additional key words: 3-hexen-1-ol, ellagic acid, Fragaria $\times$ ananassa, gallic acid, sesquiterpene

\section{Introduction}

Plants contain a wide variety of phenolic compounds, and approximately 10,000 individual compounds have been identified in various plants (Fiehn, 2001). The phenolic compounds range from simple molecules such as phenolic acids to highly polymerized compounds such as tannins. Those compounds, reported to have various biological effects, are important for both plant and animal health (Dixon and Sumner, 2003; Dixon et al., 1999, 2002). Strawberry (Fragaria $\times$ ananassa Duch.) fruit is a valuable vegetable to intake various nutrients such as vitamins, minerals, and phenolic compounds (Hannum, 2004; Meyers et al., 2003; Prior and Cao, 2000). Machiex et al. (1990) reported that strawberry fruits contain innumerable phenolic compounds including hydroxycinnamic acid derivatives, hydroxybenzoic acid derivatives, flavonols, flavanols, anthocyanins, and tannins. Especially, ellagic acid, which is a phenolic lactone compound (dimeric derivative of gallic acid), possesses $51 \%$ of total phenolic compounds in ripe strawberry fruits (Häkkinen et al., 2000).

The volatile organic compounds emitted from plant tissues are not only a fundamental flavor and fragrance constituents, as an indicator of ripeness and an attractant of pollinators, but also antimicrobial agents against pathogenic fungi and bacteria (Arroyo et al., 2007). These volatile compounds can be extracted from variety of parts of plants, such as buds, fruits, seeds, leaves, peels, woods, and roots. They are generally classified into 12 groups including organic acids, aldehydes, ketones, alcohols, esters, lactones, sulfur compounds, acetals, furans, phenols, terpenes, and epoxides (Aharoni et al., 2004),

\footnotetext{
*Corresponding author: changhoo@snu.ac.kr

${ }^{\dagger}$ These authors are contributed equally to this work.

※ Received 24 October 2012; Revised 12 November 2012; Accepted 21 November 2012. This study was supported by "Regional Joint Agricultural Research Project of RDA (granted No. 20110801030507)” granted by RDA, Korea.
} 
whereas the metabolic pathways of many volatile compounds were not fully studied. More than 300 volatile compounds including methyl butanoate, ethyl butanoate, methyl hexanoate, hexyl acetate and ethyl hexanoate have been identified in ripe strawberry fruits (Zabetakis and Holden, 1997).

On the other hand, little information is only available on contents of phenolic and volatile compounds in non-edible parts (e.g., leaf, petiole, runner, root, and unripe fruit) of strawberry plant because the compounds in strawberry plants have been mainly studied focusing on edible parts (ripe fruit). Various non-edible parts of strawberry plants, which has a harvest index below 30 (Fernandez et al., 2001), are dumped after last harvest. However, many studies showed that non-edible parts of vegetables include higher contents of phenolic or volatile compounds than edible parts. For example, the leaf of carrot was reported to contain 12 times higher contents of total phenolic acid than the root (Kähkönen et al., 1999), and the leaf of red spring onion contained kaempferol, which was not found in the edible bulb (Nuutila et al., 2002). With these research background, the objective of the present study was to identify the contents of secondary metabolites which can be used as raw materials for antioxidant and anti-flammatory agents and essential oils from edible and non-edible parts of strawberry plants.

\section{Materials and Methods}

\section{Plant Materials}

'Seolhyang' strawberry plants were grown in a greenhouse located in Suwon, Korea (37 $16^{\prime} 12 \mathrm{~N}, 126^{\circ} 59^{\prime} 20^{\prime \prime} \mathrm{E}$, and elevation $30 \mathrm{~m})$. The strawberry plants were grown in 800 $\times 300 \times 200 \mathrm{~mm}(\mathrm{~L} \times \mathrm{W} \times \mathrm{H}$, outside $)$ plastic containers filled with a mixture $(1: 1, \mathrm{v} / \mathrm{v})$ of peatmoss $(\mathrm{BM}-4$, Berger Peat Moss Ltd., Quebec, Canada) and perlite (Part No. 3, Kyung Dong Ceratech Co., Ltd., Seoul, Korea). The plants were fertigated with $450 \mathrm{~mL} \mathrm{~d}^{-1} /$ plant with Yamasaki nutrition solution $\left(\mathrm{N}, 5.5 \mathrm{me} \cdot \mathrm{L}^{-1}\right.$; $\mathrm{P}, 1.5 \mathrm{me} \cdot \mathrm{L}^{-1}$; K, $3.0 \mathrm{me} \cdot \mathrm{L}^{-1}$; $\mathrm{Ca}, 2.0$ $\mathrm{me} \cdot \mathrm{L}^{-1}$; $\left.\mathrm{Mg}, 1.0 \mathrm{me} \cdot \mathrm{L}^{-1} ; \mathrm{S}, 1.0 \mathrm{me} \cdot \mathrm{L}^{-1}\right)$ using an automatic drip fertigation system (Agro 5000, Agro Co., Ltd., Wonju, Korea). Roots, unfolded leaves, and petioles of mother plants, runners, and folded leaves of runner plants were harvested on Sep. 3, 2011 (when only first runner plants were produced but not second runner plants); unfolded leaves, petioles, and unripe and ripe fruits were harvested on Nov. 16, 2012.

'Seolhyang' strawberry fruits were classified into two ripening stages by percentage of red color: $0 \%$ red color (Unripe); $100 \%$ red color (Ripe). Then, surface color of the classified fruits was measured using a chromameter (CR-300, Minolta Camera Co., Ltd., Osaka Japan) and chromaticity a* (red-green) in CIE scale was determined. Color values were recorded on one zone from each of three fruits. After classification, samples were stored at $-20^{\circ} \mathrm{C}$ until phytochemical analysis.

\section{Analysis of Phenolic Compounds}

Phenolic compounds were extracted and hydrolyzed according to the procedure of Nuutila et al. (2002). Different parts (200 $\mathrm{mg}$ ) of strawberry plant were homogenized with $5 \mathrm{~mL}$ of $1.2 \mathrm{M} \mathrm{HCl}$ in $50 \%(\mathrm{v} / \mathrm{v})$ aqueous methanol. As an antioxidant $8 \mathrm{mg}$ of ascorbic acid was added to the hydrolysis mixture and this process was performed in triplicate. After refluxing at $80^{\circ} \mathrm{C}$ for $2 \mathrm{~h}$, the extract was cooled, made up to $10 \mathrm{~mL}$, and sonicated for $3 \mathrm{~min}$. The extract was filtered through a $0.45 \mu \mathrm{m}$ syringe filter before injection to the HPLC apparatus (Ultimate 3000, Dionex, Sunnyvale, CA, USA). The mobile phase was a $25 \mathrm{~min}, 20-60 \%$ gradient of methanol in water with $300 \mathrm{~mL} \cdot \mathrm{L}^{-1}$ trifluoroacetic acid, eluted at a flow rate of $0.8 \mathrm{~mL} \cdot \mathrm{min}^{-1}$. After each analysis, the column was washed with $100 \%$ methanol for $2 \mathrm{~min}$, returned to $20 \%$ methanol, and re-equilibrated for $10 \mathrm{~min}$ before the next analysis. The eluted components were monitored using a UV/Vis detector at 280 and $340 \mathrm{~nm}$ with a Zorbax SB C-18 column, $150 \times$ $4.6 \mathrm{~mm}$, i.d. $5 \mu \mathrm{m}$ (Agilent Co., New York, NY, USA). Analytical standards were trans-cinnamic acid, $p$-coumaric acid, caffeic acid, gallic acid, ellagic acid, 2,5-hydrobenzoic acid, 3,4-

hydrobenzoic acid, kaempferol, and quercetin, which were purchased from Sigma-Aldrich Co. (St. Luis, MO, USA) and $p$-hydrobenzoic acid was purchased from Samchun Pure Chemical Co. (Pyeongtaek, Korea).

\section{Analysis of Volatile Organic Compounds}

Volatile organic compounds were measured using the method of Isleten and Karagül-Yüceer (2008). The sample gas was collected by Tenax-TA (PerkinElmer Life and Analytical Sciences Inc., Waltham, MA, USA), the dynamic thermal extractor chamber system, which is composed of a $26 \mathrm{~mL}$ glass tube and the air control system, including an air supply unit and pumps. Purified nitrogen gas $\left(39 \mathrm{~mL} \cdot \mathrm{min}^{-1}\right)$ was used for ventilation. Volatile organic compounds in different parts of strawberry plant were analyzed by thermal desorption gas chromatograph mass spectrometer (TDS-GC MSD and TDS2, Gerstel GmbH \& Co. KG, Mülheim, Germany; 6890N and 5975, Agilent Technologies, Inc. Santa Clara, CA, USA).

\section{Statistical Analysis}

Statistical analyses were performed using the SAS statistical software, release 9.2 (SAS Institute Inc., Cary, NC, USA). Duncan's multiple range test was used to assess differences in contents of ellagic and gallic acids. Significant differences 
were statistically considered at $P \leq 0.05$.

\section{Results and Discussion}

\section{The Contents of Phenolic Compounds at Various Plant Parts}

Parts of 'Seolhyang' strawberry plants during vegetative propagation showed significant differences in the contents of ellagic and gallic acid. Other phenolic compounds, however, were not detected. Häkkinen et al. (1998) reported that extraction and hydrolysis method influence the diversity of the phenolic compounds extracted from strawberry fruits. The content of ellagic acid was $2.25 \pm 0.78,4.25 \pm 2.37$, $2.67 \pm 0.64,3.74 \pm 0.69$, and $7.36 \pm 1.10 \mathrm{mg} \cdot \mathrm{g}^{-1}$ (fresh weight) in roots, leaves and petioles of mother plants, runners, and leaves of runner plants, respectively (Table 1). The content of ellagic acid in leaves and petioles of mother plants was two to three times lower than that in leaves and petioles of strawberry plant during reproductive growth (Tables 1 and 2). The content of gallic acid was $0.94 \pm 0.21,2.05$ $\pm 1.05,1.32 \pm 0.40,1.62 \pm 0.42$, and $5.07 \pm 3.66 \mathrm{mg} \cdot \mathrm{g}^{-1}$ (fresh weight) in roots, leaves and petioles of mother plants, runners, and leaves of runner plants, respectively (Table 1). The results indicated that the contents of ellagic and gallic acid in leaves of runner plants were higher than those in other parts. The difference of the contents of the phenolic compounds between the leaves of mother and runner plants may be the cause of leaf age (unfolded or folded). Wang and Lin (2000) reported that young leaves (from the upper part of shoots or stems) of strawberry plants contained higher content of total phenolic compounds than old leaves (from the lower part of shoots or stems). Nantitanon et al. (2010) found that young leaves (from the apex of the branch) of guava (Psidium guajava L.) contained higher contents of ellagic and gallic acids than old leaves (from the branch position close to the stem). Young leaves of Arabidopsis also have very diverse secondary metabolites compared to old leaves, presumably due to the re-allocation of metabolites to reduce feeding by herbivores (Brown et al., 2003).

Parts of 'Seolhyang' strawberry plants during reproductive growth showed significant differences in the contents of ellagic and gallic acid. Hunter's $a^{*}$ value of unripe and ripe fruits was $-13.21 \pm 0.94$ and $36.56 \pm 1.72$, respectively. The content of ellagic acid was $12.96 \pm 2.30,5.36 \pm 0.53,5.11$ \pm 2.25 , and $2.04 \pm 0.40 \mathrm{mg} \cdot \mathrm{g}^{-1}$ (fresh weight) in leaves, petioles, and unripe and ripe fruits, respectively (Table 2). The content of ellagic acid in leaves and fruits of 'Seolhyang' strawberry plants was higher than in those of other cultivars. The ripe fruits, moreover, included higher ellagic acid than those of same cultivar (Kim et al., 2011). The results showed that different hydrolysis conditions significantly change the content of ellagic acid obtained (da Silva Pinto et al., 2008). The content of ellagic acid was higher in vegetative organs than in reproductive organs. Maas et al. (1991) found that the content of ellagic acid in leaves of 35 strawberry cultivars was higher than that in unripe and ripe fruits. Blackberry and raspberry also showed similar trend (Wang and Lin,

Table 1. The contents of phenolic compounds in different parts of strawberry 'Seolhyang' plants cultivated in greenhouse with hydroponic culture during vegetative propagation.

\begin{tabular}{lcc}
\hline \hline \multirow{2}{*}{ Part } & \multicolumn{1}{c}{ The contents of phenolic compounds $\left(\mathrm{mg} \cdot \mathrm{g}^{-1} \mathrm{FW}\right)$} \\
\cline { 2 - 3 } & Ellagic acid & Gallic acid \\
\hline Roots of mother plants & $2.25 \pm 0.78 \mathrm{~d}^{2}$ & $0.94 \pm 0.21 \mathrm{~b}$ \\
Leaves of mother plants & $4.25 \pm 2.37 \mathrm{~b}$ & $2.05 \pm 1.05 \mathrm{~b}$ \\
Petioles of mother plants & $2.67 \pm 0.64 \mathrm{~cd}$ & $1.32 \pm 0.40 \mathrm{~b}$ \\
Runners & $3.74 \pm 0.69 \mathrm{bc}$ & $1.62 \pm 0.42 \mathrm{~b}$ \\
Leaves of runner plants & $7.36 \pm 1.10 \mathrm{a}$ & $5.07 \pm 3.66 \mathrm{a}$ \\
\hline
\end{tabular}

${ }^{z}$ Mean separation within columns by Duncan's multiple range test at $P=0.05$.

Table 2. The contents of phenolic compounds in different parts of strawberry 'Seolhyang' plants cultivated in greenhouse with hydroponic culture during reproductive growth.

\begin{tabular}{lcr}
\hline \hline \multirow{2}{*}{ Part } & The contents of phenolic compounds $\left(\mathrm{mg} \cdot \mathrm{g}^{-1} \mathrm{FW}\right)$ \\
\cline { 2 - 3 } & Ellagic acid & Gallic acid \\
\hline Leaves & $12.96 \pm 2.30 \mathrm{a}^{\mathrm{z}}$ & $1.88 \pm 0.32 \mathrm{~b}$ \\
Petioles & $5.36 \pm 0.53 \mathrm{~b}$ & $0.91 \pm 0.13 \mathrm{c}$ \\
Unripe fruits & $5.11 \pm 2.25 \mathrm{bc}$ & $2.75 \pm 0.48 \mathrm{a}$ \\
Ripe fruits & $2.04 \pm 0.40 \mathrm{~d}$ & $0.35 \pm 0.03 \mathrm{~d}$ \\
\hline
\end{tabular}

${ }^{z}$ Mean separation within columns by Duncan's multiple range test at $P=0.05$. 
2000). Among the vegetative organs, leaves contained higher content of ellagic acid than petioles. There was significant differences among reproductive organs. The content of ellagic acid in unripe fruits was 2.5 times higher than that in ripe fruits. Previous studies have indicated that, in most cases, the content of ellagic acid in unripe fruit was higher than that in ripe fruit (Fait et al., 2008; Maas et al., 1991; Williner et al., 2004). The content of gallic acid was 1.88 $\pm 0.32,0.91 \pm 0.13,2.75 \pm 0.48$, and $0.35 \pm 0.03 \mathrm{mg} \cdot \mathrm{g}^{-1}$ (fresh weight) in leaves, petioles, and unripe and ripe fruits, respectively (Table 2). The content of gallic acid, in each part, was lower than that of ellagic acid. The content of gallic acid in unripe fruits was 7.9 times higher than that in ripe fruits. This is in agreement with previous research for the content of gallic acids in strawberries (Fait et al., 2008). The results indicated that ripe fruits, the edible part of strawberry plants, presented lower values for the contents of ellagic and gallic acid than the other parts. Fait et al. (2008) also observed that the contents of ellagic and gallic acids decreased through the fruit development process.

\section{The Contents of Volatile Organic Compounds at Various Plant Parts}

'Seolhyang' strawberry plants during vegetative propagation

Table 3. The contents of volatile organic compounds $\left(\mathrm{mg} \cdot \mathrm{m}^{-3} \mathrm{FW}\right)$ in different parts of strawberry 'Seolhyang' plants cultivated in greenhouse with hydroponic culture during vegetative propagation.

\begin{tabular}{|c|c|c|c|c|c|}
\hline Volatile compound & $\begin{array}{c}\text { Roots of } \\
\text { mother plants }\end{array}$ & $\begin{array}{l}\text { Leaves of } \\
\text { mother plants }\end{array}$ & $\begin{array}{c}\text { Petioles of } \\
\text { mother plants }\end{array}$ & Runners & $\begin{array}{l}\text { Leaves of } \\
\text { runner plants }\end{array}$ \\
\hline 1-Hexene & $\mathrm{ND}^{\mathrm{z}}$ & 0.027 & ND & ND & 0.014 \\
\hline 2-Hexenal & ND & 0.019 & ND & ND & 0.013 \\
\hline 3-Hexen-1-ol & ND & 0.346 & ND & 0.008 & 0.777 \\
\hline Nonanal & ND & 0.006 & 0.003 & 0.005 & 0.003 \\
\hline Decanal & ND & 0.003 & ND & ND & ND \\
\hline Acetic acid & ND & 0.004 & ND & ND & 0.005 \\
\hline 1,4-Cyclohexanedimethanol & 0.007 & ND & ND & ND & ND \\
\hline Cyclohexanol & 0.024 & ND & ND & ND & ND \\
\hline Ethanol & 0.006 & ND & ND & ND & ND \\
\hline Furan & ND & 0.065 & ND & ND & ND \\
\hline Phenol & ND & 0.012 & 0.011 & 0.003 & ND \\
\hline 4-Pentenal & ND & 0.057 & ND & ND & 0.022 \\
\hline 4,7-Methano-1H-inden-1-ol & 0.004 & ND & ND & ND & ND \\
\hline Ether & 0.020 & ND & ND & ND & ND \\
\hline Propanoic acid & 0.007 & ND & ND & ND & ND \\
\hline 6-Methyl-5-hepten-2-one & ND & 0.004 & ND & ND & ND \\
\hline Z-3-Hexenyl tiglate & ND & 0.006 & ND & ND & ND \\
\hline$Z$ and $E$ Epoxy-ocimene & ND & 0.003 & ND & ND & ND \\
\hline trans-Caryophyllene & ND & 0.015 & ND & ND & 0.004 \\
\hline 2,6-Dimethyl-1,3,5,7-octatetraene & 0.018 & ND & ND & ND & ND \\
\hline $1,3,6$-Octatriene & ND & 0.030 & ND & ND & 0.016 \\
\hline Benzene & ND & ND & 0.003 & 0.003 & ND \\
\hline E,E-alpha-Farnesene & ND & 0.153 & ND & ND & 0.059 \\
\hline Methane & 0.004 & ND & 0.006 & ND & ND \\
\hline Octadecane & ND & 0.005 & ND & ND & ND \\
\hline Heptadecane & ND & 0.003 & ND & ND & ND \\
\hline Tetradecane & ND & ND & 0.009 & ND & ND \\
\hline Pentadecane & ND & ND & 0.006 & ND & ND \\
\hline 1-Hexenel & ND & ND & ND & ND & ND \\
\hline Methylene chloride & ND & 0.004 & 0.003 & 0.006 & 0.003 \\
\hline Bicyclo[4.3.0]nona-3,7-diene & ND & ND & ND & 0.006 & ND \\
\hline 1-Chloroheptafluorobut-2-ene & ND & ND & 0.004 & ND & ND \\
\hline delta-3-Carene & ND & 0.020 & ND & ND & ND \\
\hline Total volatile organic compounds & 0.090 & 0.782 & 0.045 & 0.038 & 0.916 \\
\hline
\end{tabular}

${ }^{\mathrm{z}} \mathrm{ND}$, non-detected. 
included 32 volatile organic compounds. The contents of total volatile organic compounds were $0.090,0.782,0.045$, 0.038 , and $0.916 \mathrm{mg} \cdot \mathrm{m}^{-3}$ (fresh weight) in roots, leaves and petioles of mother plants, runners, and leaves of runner plants, respectively (Table 3). The 3-hexen-1-ol, a naturally occurring alcohol, was the predominant volatile organic compound in the leaves of mother and runner plants; however, it was not detected in roots and petioles of mother plants. Leaves of mother and runner plants, included two sesquiterpenes such as E,E-alpha-farnesene and trans-caryophyllene which are not found in leaves during reproductive growth. E,E-alpha-Farnesene that is biosynthesized via the mevalonate pathway (Pechous and Whitaker, 2004) is a floral volatile organic compound and is known as the predominant terpene produced during storage of apple fruits (Huelin and Murray, 1966). However, in this study, the content of E,E-alphafarnesene in leaves of mother plants was 2.6 times higher than that in ripe fruits. In addition, monoterpene (delta-3Carene; $0.020 \mathrm{mg} \cdot \mathrm{m}^{-3}$ ) was only detected in leaves of mother plants. The results showed that leaves of runner plants contained the highest contents of total volatile organic compounds, and leaves of mother plants contained diverse volatile organic compounds.

Table 4. The contents of volatile organic compounds $\left(\mathrm{mg} \cdot \mathrm{m}^{-3} \mathrm{FW}\right)$ in different parts of strawberry 'Seolhyang' plants cultivated in greenhouse with hydroponic culture during reproductive growth.

\begin{tabular}{|c|c|c|c|c|}
\hline Volatile compound & Leaves & Petioles & Unripe fruits & Ripe fruits \\
\hline Hexanal & $N D^{z}$ & ND & ND & 0.053 \\
\hline 2-Hexenal & ND & ND & ND & 0.238 \\
\hline 2-Hexen-1-ol & ND & ND & ND & 0.113 \\
\hline 3-Hexen-1-ol & ND & ND & 0.026 & ND \\
\hline Octanal & ND & ND & 0.006 & ND \\
\hline Nonanal & 0.023 & 0.022 & 0.038 & 0.028 \\
\hline Decanal & 0.013 & 0.010 & 0.019 & 0.015 \\
\hline Acetic acid & ND & ND & ND & 3.155 \\
\hline Phenol & 0.009 & ND & 0.026 & 0.011 \\
\hline Propanoic acid & ND & ND & ND & 0.109 \\
\hline 6-Methyl-5-hepten-2-one & ND & ND & 0.009 & ND \\
\hline 2-Butanone & ND & ND & ND & 0.030 \\
\hline 2-Pentanone & ND & ND & ND & 0.025 \\
\hline Methyl thiolacetate & ND & ND & ND & 0.020 \\
\hline n-Propyl acetate & ND & ND & ND & 0.010 \\
\hline Butanoic acid & ND & ND & ND & 2.419 \\
\hline Isopropyl butanoate & ND & ND & ND & 0.010 \\
\hline Methyl crotonate & ND & ND & ND & 0.006 \\
\hline Hexanoic acid & ND & ND & ND & 0.421 \\
\hline E-2-Hexenyl butanoate & ND & ND & ND & 0.009 \\
\hline 4-Heptanone & ND & ND & ND & 0.014 \\
\hline Nonanoic acid & ND & ND & ND & 0.011 \\
\hline Decanoic acid & ND & ND & ND & 0.007 \\
\hline Disulfide & ND & 0.048 & ND & ND \\
\hline Sulfurous acid & ND & ND & 0.006 & ND \\
\hline Benzene & 0.010 & ND & ND & ND \\
\hline E,E-alpha-Farnesene & ND & ND & ND & 0.060 \\
\hline Tetradecane & ND & ND & 0.007 & ND \\
\hline Methylene chloride & ND & ND & ND & ND \\
\hline delta-3-Carene & ND & ND & ND & 0.040 \\
\hline 1-Butanol & ND & ND & ND & 0.010 \\
\hline 2-Butanol & 0.010 & ND & 0.011 & ND \\
\hline Cyclotrisiloxane & ND & ND & ND & 0.008 \\
\hline Toluene & ND & 0.006 & ND & ND \\
\hline Butane & 0.006 & ND & ND & ND \\
\hline Octane & 0.014 & ND & 0.006 & ND \\
\hline Total volatile organic compounds & 0.084 & 0.086 & 0.154 & 6.949 \\
\hline
\end{tabular}

${ }^{\mathrm{z}} \mathrm{ND}$, non-detected. 
'Seolhyang' strawberry plants during reproductive growth included 36 volatile organic compounds. The contents of total volatile organic compounds were $0.084,0.086,0.154$, and $6.949 \mathrm{mg} \cdot \mathrm{m}^{-3}$ (fresh weight) in leaves, petioles, and unripe and ripe fruits, respectively (Table 4). These results were directly opposite to the content of ellagic acid in parts of strawberry plants during reproductive growth. Carboxylic acids such as acetic acid (45.4\%) and butanoic acid (34.8\%) were the predominant volatile organic compounds in the ripe fruits, while they were detected only in ripe fruits. On the other hand, ripe fruits of 'Bogyojosaeng' and 'Suhong' cultivars mainly included butylbenzene (19.0\%) and E-nerolidol (12.4\%), respectively (Park et al., 2000). Furthermore, ripe fruits of 'Seolhyang' strawberry plants included monoterpene (delta-3-Carene; $0.040 \mathrm{mg} \cdot \mathrm{m}^{-3}$ ) and sesquiterpene (E, E-alpha-Farnesene; $0.060 \mathrm{mg} \cdot \mathrm{m}^{-3}$ ), which were not found in the other parts. Fruit tissues of strawberry showed strong upregulated expression of some terpene synthase gene homologs in the receptacle tissue during ripening; an RNA gel blot research confirmed the increase in the terpene synthase transcript levels during fruit ripening, whereas no expression could be detected in leaf tissue (Aharoni et al., 2004).

Ellagic and gallic acids in strawberry fruits have been known to have antimutagenic, antioxidant, and anti-inflammatory activities in the mammalian systems. In addition, volatile organic compounds in strawberry fruits can be considered as the antifungal agent (Arroyo et al., 2007). However, product yield of strawberry fruits is insufficient to meet a demand. Results indicate that non-edible parts of strawberry plants include higher contents of phenolic and volatile organic compounds than the other parts, regardless of season. Thus, after production of fruits or runner plants was finished, non-edible parts (e.g., leaves and unripe fruits) of strawberry plants can be used as a raw material for antioxidant or anti-inflammatory agents, and edible parts (i.e., ripe fruits) can be available for making an essential oil.

\section{Literature Cited}

Aharoni, A., A.P. Giri, F.W.A. Verstappen, C.M. Bertea, R. Sevenier, Z. Sun, M.A. Jongsma, W. Schwab, and H.J. Bouwmeester. 2004. Gain and loss of fruit flavor compounds produced by wild and cultivated strawberry species. Plant Cell 16:3110-3131.

Arroyo, F.T., J. Moreno, P. Daza, L. Boianova, and F. Romero. 2007. Antifungal activity of strawberry fruit volatile compounds against Colletotrichum acutatum. J. Agric. Food Chem. 55:5701-5707.

Brown, P.D., J.G. Tokuhisa, M. Reichelt, and J. Gershenzon. 2003.
Variation of glucosinolate accumulation among different organs and developmental stages of Arabidopsis thaliana. Phytochemistry 62:471-481.

da Silva Pinto, M., F.M. Lajolo, and M.I. Genovese. 2008. Bioactive compounds and quantification of total ellagic acid in strawberries (Fragaria $\times$ ananassa Duch.). Food Chem. 107:1629-1635.

Dixon, R.A. and L.W. Sumner. 2003. Legume natural products: Understanding and manipulating complex pathways for human and animal health. Plant Physiol. 131:878-885.

Dixon, R.A., L. Achnine, P. Kota, C.J. Liu, M.S. Reddy, and L. Wang. 2002. The phenylpropanoid pathway and plant defense: A genomics perspective. Mol. Plant Pathol. 3:371-390.

Dixon, R.A., P. Canovas, Z.J. Guo, X.Z. He, C. Lamb, and F. McAlister. 1999. Molecular controls for isoflavonoid biosynthesis in relation to plant and human health, p. 133-160. In: J.T. Romeo (ed.). Phytochemistry in human health protection, nutrition, and plant defence. Recent Advances in Phytochemistry. Vol 33. Kluwer Academic/Plenum Publ., NY, USA

Fait, A., K. Hanhineva, R. Beleggia, N. Dai, I. Rogachev, V.J. Nikiforova, A.R. Fernie, and A. Aharoni. 2008. Reconfiguration of the achene and receptacle metabolic networks during strawberry fruit development. Plant Physiol. 148:730-750.

Fernandez, G.E., L.M. Butler, and F.J. Louws. 2001. Strawberry growth and development in an annual plasticulture system. HortScience 36:1219-1223.

Fiehn, O. 2001. Combining genomics, metabolome analysis, and biochemical modeling to understand metabolic networks. Comp. Funct. Genom. 2:155-168.

Häkkinen, S.H., S.O. Kärenlampi, H.M. Mykkänen, I.M. Heinonen, and A.R. Törrönen. 2000. Ellagic acid content in berries: Influence of domestic processing and storage. Eur. Food Res. Technol. 212:75-80.

Häkkinen, S.H., S.O. Kärenlampi, I.M. Heinonen, H.M. Mykkänen, and A.R. Törrönen. 1998. HPLC method for screening of flavonoids and phenolic acids in berries. J. Sci. Food Agric. 77:543-551.

Hannum, S.M. 2004. Potential impact of strawberries on human health: A review of the science. Crit. Rev. Food Sci. Nutr. 44:1-17.

Huelin, F.E. and K.E. Murray. 1966. $\alpha$-Farnesene in the natural coating of apples. Nature 210:1260-1261.

Isleten, M. and Y. Karagül-Yüceer. 2008. Effects of functional dairy based proteins on nonfat yogurt quality. J. Food Quality 31:265-280

Kähkönen, M.P., A.I. Hopia, H.J. Vuorela, J.P. Rauha, K. Pihlaja, T.S. Kujala, and M. Heinonen. 1999. Antioxidant activity of plant extracts containing phenolic compounds. J. Agric. Food Chem. 47:3954-3962.

Kim, S.K., R.N. Bae, and C. Chun. 2011. Changes in bioactive compounds contents of 'Maehyang' and 'Seolhyang' strawberry fruits by UV light illumination. Kor. J. Hort. Sci. Technol. 29:172-180.

Machiex, J.J., A. Fleuriet, and J. Billot. 1990. Fruit phenolics. CRC Press, Boca Raton, FL, USA.

Maas, J.L., S.Y. Wang, and G.J. Galletta. 1991. Evaluation of strawberry cultivars for ellagic acid content. HortScience 


\section{6:66-68.}

Meyers, K.J., C.B. Watkins, M.P. Pritts, and R.H. Liu. 2003. Antioxidant and antiproliferative activities of strawberries. J. Agric. Food Chem. 51:6887-6892.

Nantitanon, W., S. Yotsawimonwat, and S. Okonogi. 2010. Factors influencing antioxidant activities and total phenolic content of guava leaf extract. LWT - Food Sci. Technol. 43:1095-1103.

Nuutila, A.M., K. Kammiovirta, and K.M. Oksman-Caldentey. 2002. Comparison of methods for the hydrolysis of flavonoids and phenolic acids from onion and spinach for HPLC analysis. Food Chem. 76:519-525.

Park, E.R., H.J. Lee, and K.S. Kim. 2000. Volatile flavor components in Bogyojosaeng and Suhong cultivars of strawberry (Fragaria ananassa Duch.). J. Food Sci. Nutr. 5:119-125.
Pechous, S.W. and B.D. Whitaker. 2004. Cloning and functional expression of an (E,E)- $\alpha$-farnesene synthase cDNA from peel tissue of apple fruit. Planta 219:84-94.

Prior, R.L. and G. Cao. 2000. Flavonoids: Diet and health relationships. Nutr. Clin. Care. 3:279-288.

Wang, S.Y. and H.S. Lin. 2000. Antioxidant activity in fruits and leaves of blackberry, raspberry, and strawberry varies with cultivar and developmental stage. J. Agric. Food Chem. 48:140-146.

Williner, M.R., M.E. Pirovani, and D.R. Güemes. 2004. Ellagic acid content in strawberries of different cultivars and ripening stages. J. Sci. Food Agric. 83:842-845.

Zabetakis, I. and M. Holden. 1997. Strawberry flavour: Analysis and biosynthesis. J. Sci. Food Agric. 74:421-434. 